\title{
MEDITACION DEL CHACO Y AMERICA EN LA OBRA DE UN PINTOR ARGENTINO
}

\author{
Por María Luisa ACUÑA
}

\section{INTRODUCCION}

El tema de este trabajo es la trayectoria de un pintor chaqueño y la significación de su obra, cuya calidad artistica ha sido ampliamente valorada por la critica y muchas veces premiada en el orden provincial, regional y nacional, hasta recibir en 1980 el Premio Anual de la Fundación Susana Glombovsky, que se confiere "a la labor de toda una vida consagrada al arte y la cultura del Chaco", según dice su Estatuto.

La genealogia de Rodolfo Schenone lo enraiza con Italia, España y América. Su genealogía artística lo integra a una importante corriente de arte argentino: los pintores del Litoral, Supisiche, Gambartes, Matías Molina. En la historia del arte chaqueño, aún no escrita, habrá que ubicar primero a la generación de los "pioneros", Alfredo Pértile, Carlos H. Schenone, Crisanto Dominguez, Juan de Dios Mena, aunque no todos chaqueños, todos empeñados en thacer Chaco", y deșpués, irá la generación de artistas chaqueños con Rodolfo Schenone, Ricardo Jara, Oscar Sánchez, Susana Geraldi, Fabriciano Gómez y otras.

La pintura de Rodolfo Schenone por su temática y su cromatismo vibrante, cálido, luminoso que muestra la fuerza de su raíz indigena, pertenece a una corriente de expresión americana. El mensaje de sus imágenes alcanza dimensión universal cuando, a partir de los problemas del hombre chaqueño invita a meditar sobre l Hombre agredido por la violencia del hombre, la desmesurada evolución tecnológica sin ningún freno moral, el delicado equilibrio, tantas veces roto, de la paz mundial.

Hemos desarrollado nuestro tema en tres partes subtituladas: el medio, el artista, la obra; cada una explica e implica a la otra y las tres hacen el todo. Imágenes, colores, Iuces, soles de la infancia, forman el hontanar de la memoria del artista, porqueiél pinta de memoria, sin modelos.

La gran tección que su padre, lescultor Carlos H. Schenone le dejara de una entrega fervorosa al arte trabajando con autenticidad $y$ amor sin buscar riqueza, ni fama, orienta su vida consagrada al arte y la docencia en el Taller de Artes Visuales, mientras se mantiene sencillamente de su cargo de Secretario Administrativo en ita Facultad de Humanidades de la Universidad Nacional del Nordeste. 
Sin compromisos ideológicos, tiene un compromiso humano conforme al cual define la pintura y al artista con las siguientes palabras:

"La pintura no es solamente estética, sino ética, moral ante el mundo, es el compromiso de vida que nos nutre y nos proyecta hacia la perfección".

"Convivir con el arte es vivir en compromiso total con la vida del hombre y la trascendencia de los valores humanos, más allá de la materia, hasta las raíces mismas del ser".

\section{EL MEDIO}

La llanura chaqueña es una continuación de la santafesina; pero cambia la fisonomía amable de la pampa húmeda por un gesto adusto que, sin ser descortés, invita a una consideración más seria de la vida. La tierra es suelta, muy suelta, gris, penetra todo y cubre con una pátina opaca los verdes del monte a la vera de los caminos y rutas. Pero cuando un soplo de viento al atardecer, mientras el sol hecho un globo de fuego desciende en el poniente, si un soplo alborota al polvo, se levanta una nube rosada, transparente, que hace irreales, ideales a los hombres, los ranchos y los árboles del monte. Entonces el hombre olvida la realidad cotidiana de necesidad acuciante, para percibir la poesía del momento. porque en pocos minutos el sol desaparece dejando que las nubes tiñan demoradamente de carmesi las paredes de los ranchos. $Y$ en los amaneceres, cuando la tierra empieza a despertar, una niebla se levanta de esteros, lagunas y ríos; esa niebla se empurpura con la luz del sol naciente y sonroja a las garzas blancas posadas en las totoras y cortaderas próximas al agua.

Sin embargo la vida es dura para el hombre en esta región que combina la adustez de árboles y arbustos punzantes como el palo mataco y los caraguatás con la gracia tierna de un camalote lleno de flores lilas flotando a la deriva en el Paraná. El hombre debe trabajar mucho y rudamente para sobrevivir a una naturaleza fuerte, que tan pronto humedece sus sembrados con una lluvia de primavera, como se los anega con un diluvio invasor de algodonales y campos de pastoreo. O bien el año es tan seco, que las plantitas recién brotadas se agostan bajo el sol como devoradas por una llama ardiente. El mismo grande y hermoso Paraná, Pariente del Mar, a veces recuerda ese parentesco y se crece, desbordándose sobre los caserios costeros, o avanzando, agigantado, sobre los pueblos de la ribera.

Vida y muerte corren paralelas en esta región del país. El hombre nace y vive sabiéndolo; pero lucha y persiste a pesar de todos los desastres, las calamidades, los embates del clima, del río, de las plagas que procuran doblegarlo. El hombre sabe que vivir es duro; pero vale la pena, por eso trabaja y se esfuerza por mostrar que está vivo, que es más fuerte, que aún resiste. Vivir es resistir, tal es la divisa que todo chaqueño graba en su corazón para ejercitarla mientras perdura. Por eso la capital del Chaco se llama Resistencia. Aquí vive Rodolfo Schenone practicando esta filosofia vital. Desde aquí mira solidariamente los afanes y las luchas de los hombres, participa del desarrollo cultural de la 
ciudad y de la región. Desde aquí siente y comprende la diversidad y la unidad de América del Sur. Desde aquí reflexiona sobre los conflictos que desgarran al hombre en el planeta. Desde aquí se interroga sobre el mundo, su marcha, su destino. La ciudad de Resistencia es su base y su atalaya.

Resistencia ha sido llamada "la joven del Norte" a causa de sus pocos años de vida, algo más de cien, en comparación con ciudades centenarias como su vecina Corrientes que ha festejado ya sus cuatrocientos años. La capital chaqueña es una joven precoz porque ha desarrollado una identidad definida en el conjunto de las capitales del nordeste, tanto en lo urbanístico como en lo cultural(1). También se la conoce como "la ciudad de las estatuas" por las que tiene emplazadas en calles, avenidas y paseos públicos; hecho que ha desarrollado un sentimiento de familiaridad con el arte en sus habitantes. Anualmente se realiza el Certamen Nacional de Escultura en Madera en la Plaza 25 de Mayo, corazón de la ciudad; durante siete dias se instalan alli los escultores participantes munidos de un tronco de madera y de sus herramientas y tallan sus iconos, mientras todo Resistencia, niños, jóvenes, adultos, ancianos, al cruzar la plaza, se detienen a mirarlos, dialogar y opinar sobre las figuras en realización, para votar finalmente, cuando se clausura el certamen por la escultura de su preferencia (2). El Salón Nacional de Dibujo y Grabado, desde hace nueve años convoca anualmente en Resistencia a una calificada pléyade de dibujantes y grabadores de nítida y brillante trayectoria en el pais y en el exterior. Otra nota distintiva de la ciudad es el cultivo del canto coral, los encuentros corales, impulsados desde que la Asociación Coral Polifónica del Chaco junto con su creadora y primera Directora, Yolanda Pereno de Elizondo, hizo conocer los nombres de Chaco y Resistencia, triunfando en certámenes de Europa y América. Resistencia vive un clima propicio a las manifestaciones del espíritu (3).

\section{EL ARTISTA}

Mencionar las raíces europeas de América es un lugar común e inevitable. Nuestro trabajo necesita hacerlo ineludiblemente porque nos inspiramos en la obra de un artista del interior del pais y porque la región de donde proviene, su región, tiene rasgos que la distinguen del conjunto de regiones argentinas.

Empezaremos reconociendo que al menos dos de cada tres personas nacidas en el litoral norte argentino, en el nordeste, tienen ascendientes europeos. De estos antepasados muchos proceden de Italia, muchos también de España, sin contar a los oriundos de otras naciones europeas, integrados generosamente a la población. La denominación "gringo chaqueño" designa al criollo hijo de europeos asentados en el Chaco. Pero los habitantes del nordeste, chaqueños, misioneros, formoseños y correntinos son la amalgama de europeos, criollos e indígenas; son el producto de una síntesis vivificante y creadora.

El chaqueño ama entrañablemente a su tierra y vive impulsado por un anhelo de superación en procura de mayores logros espirituales. Esto ha sido asi desde los comienzos de la colonización. Cuenta López Piacentini refiriéndose a la 
vida de los colonos en los primeros en los primeros veinte años de su establecimiento en el interior del Chaco, que las familias se reunian por las noches a la lumbre de la lámpara de keroseme, única ituminación de la casa, para escuchar la lectura hecha por el padre de familia, o por el hijo mayor, de los libros que habian traido consigo de Europa: La Divina Comedia, la Biblia, el Quijote. Sin duda allí se estaba nutriendo el espirttu de los niños y jóvenes, futuros ciudadanos de la provincia. La tradición cultural so staba transmitiendo generacionalmente. (4)

En breve revisión genealógica ubicaremos a nuestro artista en el contexto esbozado. A comienzos de siglo en Santa Fe, Carlos Nicasio Schenone, hijo de italianos, casó con Ana Posa Araújo, santafesina, descendiente de españoles y criollos. El matrimonio tuvo cinco hijos Carlos Humberto, César Antonio, Lorenzo, Miguel y Julio. Casi por los mismos años, en Corrientes, Juan Bautista Delcett, napolltano, casó con Honoria Ramirez, correntina, descendiente de españoles e indigenas guaranies. Tuvieron cinco hijas: Flora, Meloria, Otilia, Leticia y una hermana más de muy breve vida. Flora Delcett Ramirez, nacida en Corrientes, estudió magisterio y fue designada para enseñar en una escuela de Cate Lai en el interior del Chaco, aproximadamente en 7933. Carlos Humberto Schenone Araújo, muy dotado para trabajar la madera en interesantes tallas, era viajante de comercio por aquellos años; tenía familiares establecidos en Cote Lai, su abuela paterna y un hermano de su padre, para visitarlos viajó allá y conació a Flora y su mutua simpatia:pronto se transformó en un sentimiento más hondo. El comenzó a trabajar en un abraje que "La 'Forestal" poseia en la zona, de esta manera prolongó su estadía en el pueblo y pudo, dos años más tarde, en 1935 casarse con la joven maestra correntina. Flora tha a ser madre a mediados de 1936 y se tue a la casa materna en Corrientes; alli nació el 9 de junio de 1936 su primer hijo, bautizado con el nombre de Rodolfo Oscar.

Rodolfo Oscar Schenone Delcett reúne en si las raíces española, italiana, guarani y criolla. Guando tenía dos años fue confiado a sus abuelos maternos por su madre, embarazada del segundo hijo. La residencia de Juan Bautista Delcett y Honoria estaba en la Ista de Antequera, bañada por las aguas del Paraná. Allí transcurrió la primera infancia del artista, entre los dos y los cuatro años, bajo el amoroso cuidado de sus abuelos, frente al paisaje de la costa. Los amaneceres de transparencias luminosas, ios mediodias cuando el sol bruñe de plata las aguas del río, los crepúsculos de demoradas púrpuras, llenaron de luz los ojos del niño, una luz esplendorosa que su memoria atesoró para volcarla en sus cuadros. En las noches cálidas despertaba en su pequeño lecho oyendo los gritos guturales de los monos carayás en la otra orilla del río, en medio del monte, y ya no conciliaba el sueño presintiendo su presencia misteriosa como una región fascinante. Alli empezó a descubrir el mundo en las pequeñas presencias de los pájaros de plumaje colorido, las tagartijas de pequeños ojos brillantes, los peces que pescaba el "nono". Todo era objeto de su curiosidad $v$ todas eran imágenes que su alma atesoraba calladamente.

A los años de la lsta de Antequera siguieron los años de estudios, interno en tos colegios de Don Bosco en Corrientes y Don Orione de Sáenz Peña. Tiempo de formación $\theta$ instrucción de caros recuerdos para el artista. Pero en las 
vacaciones recuperaba ol calor da su hogar; a veces se estaba junto al padre en sul taller, minándolo trabajar las maderas, aspirando aroma de las astillas de algamobo; guayacán o quebracho, djbujando como. lo veía hacer, modelando en arcilla como su padre modelaba, en fim, en esas vacaciones so definió su vocación por el arto. En aquellos dias largos do su infancia también habia tiempo para jugar con sus amigos criollos y mativos: las excursiones at monte lo revelaron las costumbres de sus habitantes, aves y animalos, sus retinas fijaron los juegos de luz solar filtrándose pon las fitondas, los tremcos y enredaderas. Sus amigos tobas y mocovies habitantes de la colonia aborigen cenca de Campo. Feldman, donde estaba la escuela dirigida por su madre, lo aproximaron a la realidad de América morena con sus rancherios pobres, su contemplar la vida en veloz cambio sin decidirse a entrar en ella. Las mujeres tobas que pueblan sus cuadros tienen esa mirada de expectativa sin fatalismo, como guardándose honde las ganas de vivir.

Cuando cumplió once años su padre le ofreció los primeros óleos y le enseñó a usarlos. Entonces empezó para el niño su descubrimiento del color como elemento fundamental de un lenguaje presentido. En otras circunstancias de tiempo y lugar habría concurrido a una escuela de bellas artes o a una academia; pero el Chaco aún no contaba con instituciones asi, y enviarlo a estudiar arte en la Capital Federal o en otra provincia estaba fuera del alcance de sus padres. Sin embargo todo fue para bien, porque tuvo maestros buenos: primero su padre y después en Resistencia, a los amigos de su padre, Juan do Dios Mena, Clement Moreau, quienes lo orientaban con sus consejos y experiencia, mientras cultivaban la amistad de Carlos $\mathrm{H}$. Schenone, puesto que el joven estaba siempre pintando cerca de su padre, ya sea en el taller de Mena, o en el campus universitario, donde estuvo instalado ef escultor desde 1958. Este año Carlos H. Schenone fue nombrado organizador y director del Taller de Arte Regional de la Universidad Nacional de Nordeste, tarea que cumplió exitosamente (5). El joven artista salió ganancioso, pofque pudo consultar y obtener respuestas inmediatas a los problemas que el cuadro le planteaba: composición, teoria del color, y otros elementos de arte le habrian sido impartidos en una academia a través de años de enseñanza. El clima cultural vivido en Resistencia era propicio para completar su formación (ต). Entre 1958 y 1960 se fue definiendo su vida; designado Habilitado Contable en la recién fundada Facultad de Humanidades, participó en su organización y alcanzó un "modus vivendi" que le permite dedicarse al arte. Tuvo una beca del Fondo Nacional de las Artes cumplida en Buenos Aires poniéndose en contacto con instituciones dedicadas a la enseñanza de las Artes Plásticas, Museos y en especial, visitas a maestros como Raúl Soldi, Luis Seoane y Horacio Butler, del último recuerda la humanidad y sencillez en el trato, aparte de su exhortación a trabajar exigiéndose la máxima autenticidad en la realización de la obra de arte, sin buscar fama, ni gloria: un pensamiento coindidente con el de su padre y el suyo propio. De vuelta a Resistencia contrajo enlace con Dolly Bernini, joven maestra chaqueña. Las responsabilidades del trabajo y del hogar se impusieron a su deseo de ser alumno del Taller de Arte Regional en el cual se habia inscrito junto con la primera promoción de alumnos; de modo que continuó perfeccionándose como autodidacta. 
El diccionario llama "autodidacta" al que se ha instruído o educado por sí mismo sin maestro o profesor. Estrictamente hablando Rodolfo Schenone no es un autodidacta, porque tuvo maestros experimentado en sus comienzos; pero si se piensa su evolución artística como el descubrimiento de si mismo, lo es. Para nosotros un autodidacta es una persona que se descubre a si misma a través de uno y mil intentos fallidos unos, acertados otros; deberá ser constante y no dejarse vencer por el desaliento; perseverante y no perdèr de vista su meta; discernir la verdad en cada critica que su obra reciba; desechar alabanzas exageradas; ser humilde para aceptar sus errores y corregirlos; ser soberbio para rechazar las posibilidades de hacerse famoso renunciando a su ideal; ser fuerte para no sucumbir a la tentación de ganar dinero con obras adocenadas. Para el verdadero artista autodidacta la vida es un agón perpetuo, porque está en lucha permanente para forjarse como un acero bien templado. En este sentido Rodolfo Schenone es un artista autodidacta, porque cultiva esta disciplina $(n$.

\section{LA OBRA}

Desde sus comienzos Rodolfo Schenone define la temática de su obra centrada en el hombre del norte, el habitante de la región nordeste, su manera de concebir la vida, su apego a sus pequeñas posesiones: rancho, canoa, enseres domésticos, su entrañable amor al terruño que le hace soportables todas las condiciones negativas del clima. La definición ontológica del chaqueño representada por el "resistir" antes aludido, es el centro de la filosofía vital que lo sostiene y lo nutre. Los óleos del artista presentan el estoicismo chaqueño, lejano eco del clásico "sustine, abstine", en las imágenes de sequia, inundación, desamparo ante los elementos, pobreza de agricultores, malloneros y pescadores; pero destacan la fortaleza del hombre aún en situaciones desventajosas, la esperanza que lo mantiene digno. Este tema de connotación geográfica claramente ubicable adquiere en el transcurso de su experiencia artística y humana, un sentido de universalidad perceptible cada vez con mayor nitidez (8).

De la problemática social del chaqueño, que comparte y presenta impregnada de proximidad o projimidad, expande la visión y el significado de su obra hacia toda América y, siempre en esta tónica, alcanza dimensión universal, porque presenta al Hombre agredido por el hombre codicioso, cercado por el monstruoso desarrollo de la técnica sin moral y también al mundo en peligro por el desequilibrio de sus ecosistemas. Su pintura no ha cambiado de protagonistas, los hombres y mujeres del Chaco siguen poblando sus cuadros, pero el mensaje ha ganado en profundidad y hace al Chaco coetáneo y prójimo de América y del mundo. Entonces el "resistir" no es sólo chaqueño, porque es la clave de la vida del hombre en el planeta. Es el lema que debemos esgrimir y ejercitar frente a la violencia, a la desmesura, al nihilismo destructor, a la corrupción y falta de ética.

Para ilustrar esta tesis presentaremos en apretada sintesis y con algunas ilustraciones, la evolución de su pintura. Nuestra periodización, arbitraria como toda sistematización, considera tres etapas. Una primera etapa va desde 1964, 
año de sus primera muestra individual, hasta 1972. En las obras de esta época el diseño es sumario, los colores predominantes, rosados y lilas, van cediendo espacio a los cálidos bermellones y naranjas.

El color como elemento fundamental de su lenguaje plástico fue tempranamente advertido por la crítica; César Magrini destaca como un rasgo de la originalidad de Schenone su valoración del color, por su exaltación que neutraliza la tristeza y la soledad de sus protagonistas (9). También son notas constantes en su obra la emoción contenida, la tensión dramática, los tipos humanos regionales, como en "Muchachas en la feria" (Ilustración № 1), óleo premiado en el VI Salón Anual del Litoral en Santa Fe, 1968. Las jóvenes tienen las formas generosas $\sin$ exuberancia de todas las mujeres de sus cuadros. En éste como en los demás, emplea los colores que desde niño lo fascinaron: los naranjas de mamones y zapallos maduros, los sepias y marrones de la tierra chaqueña, y también de la piel india, lisa y morena como las cerámicas bien cocidas.

Finalizando los años '60 se anuncia un cambio en su pintura. Sus lecturas preferidas de esta época son las obras de autores americanos, Miguel Angel Asturias, Alejo Carpentier, Juan Rulfo, y los ensayos y estudios sobre civilizaciones precolombinas. Asi va descubriendo cómo expresaron los primitivos habitantes de América su concepción del mundo, del hombre, de la vida. Se siente deslumbrado ante las imágenes de Teotihuacán, las ruinas 'mayas, el Machu Picchu peruano, porque Rodolfo Schenone es un "primitivo" por su capacidad de percepción mítico simbólica en las imágenes del mundo que lo rodea. Sin estudios de metafísica, ontología, ni simbología, para aplicarlos racionalmente a su pintura, él descubre relaciones analógicas entre seres y cosas -relaciones imperceptibles para el hombre racional común- y construye sus "mitoformas". descifrando verdades trascendentes.

Por estos días, un viaje a San Ignacio Mini, en la provincia de Misiones, le reveló una "zona sagrada" del pasado de América. Alli percibió el hálito misterioso que emana del lugar donde tantas vidas americanas y españolas se acercaron fervorosamente a Dios, al Dios cristiano y al Ñande Ru Kwaray. Se le quedaron en las retinas la "galería" destechada de columnas donde estuvieron las habitaciones de los indios evangelizados, los restos de la capilla, en especial la portada. Profundamente conmovido por la realidad esencial e intransferible de América, sintió el anhelo de encontrar imágenes significativas de su región. No quiso contar "historias", buscó descifrar esencias.

El año 1972 pinta un óleo muy adecuado para ilustrar esta etapa, "Génesis de la Tierra". (llustración Ne 2). Allí las notas simbólicas son claras: el óvulo de la Tierra en embrión, las veladuras de luz indicando su ascensión a través de los estratos, el sol como una rueda de giro vertiginoso en su corazón encendido, ubicado en el ángulo superior izquierdo en oposición al pájaro del lado derecho, donde sería lógico esperar la imagen de la luna, a causa de la veneración del sol y la luna de tantas civilizaciones en el mundo. Pero no debe olvidarse un óleo anterior a éste, "El Lucero", en el cual la estrella del alba es un 
pájaro en vuelo, visto de frente, como lo veían los tobas. El muro con improntas de siluetas humanas en actitud procesional, reverente, es tan significativo como la puerta que enmarca la figura asombrada de una persona. El paradigma es, casi seguramente, la famosa Puerta del Sol de Tiahuanacu o Tiwanaku; pero se le superpone la entrada a la capilla de San Ignacio Miní. Técnicamente hay simetría y equilibrio en la distribución de las figuras aparentemente en torno a un eje vertical. El diseño es sumario; pero los empastes modulan la materia con elaboración emocional.

La especial importancia de este cuadro radica en que por primera vez el artista ha solucionado con forma original y color, una imagen de la tierra del nordeste argentino, como sintesis de las mitologías y cosmovisiones de toda la región: están las cinco zonas del mundo toba (a saber, "cielo" con sus astros y pájaros; "tierra", con sus dos subregiones, "campo" donde viven los hombres y "monte" -presentido en el fondo oscuro verdoso- donde viven los animales; y "profundidades": "terrestres", de donde surgirá la pequeña mujer toba contenida en el óvulo a matriz misteriosa; por debajo las profundidades "acuáticas", donde habitan las criaturas de lo profundo), la tierra roja misionera, las ruinas jesuíticas como signo de la inserción de lo sagrado cristiano en lo sagrado guaraní. representado por el sol Kwaray, y el Lucero, Tapitshi o Dapitshi, toba. Lo guarani, lo toba y lo hispánico, la suma de espiritualidades que hacen al hombre de la región (10).

Schenone elabora en estos años su personal imagología en óleos como "Alma del Río hacia el Sol", "Crucifixión del Monte", "El centro del mundo", "Reencuentro con el pasado". El Sol como hierofanía, presentida tanto por mayas y aztecas, como por incas y guaranies, aparece muchas veces en sus cuadros: "Peleando con el sol", "Espectros del sol", "Corazón del cielo", "Soles y girasoles", y finalizando casi esta etapa mágico simbólica, "Padre Sol", óleo de 1976 (llustración № 3), que tiene su importancia en la obra del artista por expresar un contenido profundo $e$ intangible: lo sagrado del sol y la tierra americanos, venerados desde las religiones precolombinas, y expresados en imágenes simbólicas del más puro cuño schenoniano. En el primer plano abajo hay dos muros texturados, uno de ellos soporta un candelero de curiosa figura con una vela encendida; el otro tiene una planta umbelifera en flor con la múltiple corola orientada hacia la luz solar. El fondo es un plano cuadrangular en fuerte violeta con veladuras rojas, anaranjadas, circulares en torno a la esfera solar que corona el vértice más alto del cuadrado. El sol tiene rayos en forma de serpientes ondulantes, cinco a la derecha y cuatro a la izquierda, quedando la base y la cumbre lisas. El centro aparece estallado en una apertura negra que deja ver pequeños óvulos blancos como capullos o huevecillos, promesa de vida. El sol encendido como un ascua simboliza la vida y la muerte con la ambivalencia de lo sagrado. Las serpientes son sabiduría y su número de nueve alude al tiempo de gstación del ser humano, y quizas también, en una lectura esotérica, las nueve encarnaciones que el hombre debe vivir antes de recuperar su sitio en el Gran Alma del Mundo. Este sol, poco convencional, emite la negra silueta de un pájaro en vuelo hacia lo alto. Es la silueta de un ave de rapiña como el carancho, héroe 
cultural toba. Las transprencias luminosas que circundan al sol, prefiguran un óvalo que incluye la totalidad del cuadro, sugiriendo la idea de un ciclo temporal y vital infinitamente repetible.

Schenone alcanza con este cuadro un increíble logro: traducir en lenguaje esotérico, hecho de imágenes religiosas americanas, la doctrina del "Anima Mundi", conocida en la Antigüedad y Edad Media por orientales y europeos. Y lo hace ordenando los símbolos sagrados por via intelectiva, no racional, ni lógica. Mientras más se contempla "Padre Sol", más cerca se cree estar de alcanzar su significado trascendente. Decir con palabras este significado es tan difícil como reflejar en pocas frases la doctrina mencionada. Nuestra lectura sería aproximadamente asi: la vela es la pequeña chispa de lo divino que traemos al nacer para acrecentarlo en nuestra vida. La planta orientada hacia el sol es la vida de las criaturas, humanas, vegetales, animales, que debe transcurrir siempre con el espíritu puesto en la divinidad, para poder retornar al Gran Sol Universal (o Alma del Mundo), y alcanzar la trascendencia que nos permita, al fin, tener un vuelo de altura como el ave en que culmina el cuadro.

Superada la etapa de síntesis de símbolos precolombinos, Schenione va descubriendo que la esencia de lo americano está también en la fuerza poderosa de su Humanidad, aún no totalmente revelada; pero acrecentada, enriquecida por los aportes espirituales que le llegan de Europa, de Asia, de Africa, de todo el mundo, diversificándola $\mathrm{y}$ al mismo tiempo dando nacimiento a una nueva personalidad dinámica, creativa, esperanzada en el futuro.

El hombre y el paisaje chaqueños protagonizan de nuevo sus cuadros. La temática regional aparece tratada con profundidad significativa, conectando los problemas cotidianos de los habitantes del litoral norte con problemas del ámbito nacional y aún del mundial. El artista ha encontrado un lenguaje personal y ha descubierto que lo regional puede alumbrar lo universal. Un símbolo de impronta local puede contenerlo todo. Los hombres sufren iguales visicitudes y problemas en cualquier lugar del mundo donde les toque vivir. En 1984 pinta "Las prisiones del alma", denunciando la destrucción del Hombre por el hombre ciego de ambición por el poder y la riqueza. En 1985 rinde su personal homenaje a la juventud sacrificada en las Malvinas con el óleo "Cuando los pájaros callan"; pero los símbolos ordenados con sentido alegórico en el cuadro trascienden la circunstancia nacional para condenar a la guerra, flagelo de todas las generaciones humanas.

Inicia la década del ' 90 , artista y hombre maduro y reflexivo; pero fiel a su temática inicial: el hombre y la tierra del nordeste; fiel a su paleta baja y cálida. La figura humana está tratada ahora con menos sintesis y geometrización de contornos que en las etapas anteriores. Las reflexiones sobre la vida, el amor, la muerte, las relaciones humanas, se translucen en los titulos e imágenes de los cuadros presentados en su Muestra retrospectiva de octubre de 1992 en el Museo de Bellas Artes de la Provincia del Chaco. Mencionemos "El juego de los niños", "Presencia del pasado", "Evocaciones", "Las luces que negamos" y "Cansancio del Alma", óleo de 1992 (llustración № 4), donde son fácilmente reconocibles los rasgos que pesonalizan su obra: la emoción contenida, los tipos humanos y el 
paisaje regional; pero hay algo misterioso e inquietante impregnando la atmósfera. La obra es bella, indiscutiblemente bella al contemplarla. Una mirada detenida va revelando la conjunción de elementos opuestos: vida-muerte, diafanidad-tinieblas. Hay un silencio tenso, como si el pintor hubiera captado un fugaz instante de inmovilidad de hombres, aves, viento en el cañaveral. El suspiro contenido. Viene a nuestra memoria un pensamiento de Trias:

"una de las condiciones estëticas que hacen que una obra sea bella es su capacidad para revelar y a la vez esconder y además, también de él: algo siniestro".

"La belleza es una apariencia y un velo que escamotea nuestra visión de un abismo sin fondo y sin remisión, en el cual cede toda visión y se resquebraja todo efecto de belleza".

(Eugenio Trias, Lo Bello y lo Siniestro, Seix Barral, Barcelona, 1984).

En el "Cansancio del Alma" hay algo trágico y siniestro velado por el esplendor del cielo luminoso de atardecer; la gracia frágil de los cardenales y el pequeño gorrión, en alternancia con el retorcimiento, casi quebrado, del cañaveral seco y la mole gris oscuro casi monumento funerario del fondo. Sin embargo una vez más, las pequeñas presencias de los pájaros dan la esperanza de renacer desde ese instante doloroso hacia otro mejor.

Sumariamente hemos presentado la trayectoria de Rodolfo Schenone, cuya valoración de lo esencial en el hombre es la primera lección recibida de sus mayores y es la semilla cultivada y hecha florecer en su arte. Empieza pintando temores y esperanzas de su gente chaqueña. La afición a las cosmovisiones precolombinas lo inicia en una honda meditación de América en pos de las claves simbólicas de su pensamiento. Después crecen en profundidad su pensamiento y sentimiento de hombre y artista comprometido con el Hombre y su destino en el mundo. La marcha de su pintura es de lo regional a lo nacional, de lo nacional a lo americano, de lo americano a lo universal. El artista lucha por su verdad, proyecta la fuerza de sus ideales en procura de la salvación del Hombre por la superación de las fuerzas negativas que lo abruman.

En octubre de 1992 Rodolfo Schenone presentó en el Museo Provincial de Bellas Artes en Resistencia, su "Muestra Retrospectiva - Pintura 1952-1992". Fue un hecho artístico de primer nivel, dentro de la actividad cultural intensa y de calidad realizada en la capital chaqueña este año. Los amigos y seguidores del artista pudimos contemplar la totalidad de su trayectoria desde su adolescencia a nuestros dias. Y una vez más comprobamos la innegable fuerza creativa de su percepción mítico simbólica del mundo que lo rodea, su maestría en el empleo del color, y en especial de la luz. Aquella luz del paisaje chaqueño, deleite de su infancia, que lleva incorporada a sus retinas y a su alma; aquella luz hecha de transparencias y luminosidades exquisitas, siempre presentes en sus cuadros.

En el Catálogo el artista dedicó esta muestra a sus alumnos con palabras definidoras de su vocación docente. Desde 1965 Rodolfo Schenone integra el 
plantel docente del Taller de Artes Visuales de la U.N.N.E. Muchas generaciones de graduados en artes plásticas se han formado junto a él, alcanzando relevancia personal en el transcurso de sus respectivas trayectorias; ellos coinciden en valorar la enseñanza y apoyo recibidos del maestro Schenone. El sabe, como supo su padre, el escultor Carlos $\mathrm{H}$. Schenone, ir conduciendo al estudiante al descubrimiento paulatino de las grandes verdades del Arte con generosidad sin límites y sencillez. La sencillez del sabio.

Para concluir parece oportuno citar parte de las palabras del artista en el mencionado catálogo, porque constituyen una diáfana autodefinición:

"Me considero afortunado de haber podido conseguir algunas de las tantas metas que mi entusiasmo juvenil se proponia; pero sobre todo, porque el concretar una obra, con todas las limitaciones que ella pueda tener, me sivió para pulsar en el transcurso de mis dias, el latido invisible del mundo, acercarlo a mi corazón y tratar de extraerle su esencia. Es posible que haya logrado muy poco de ello; pero sería inmensamente feliz, si una infima parte de mi obra trascendiera para emocionar a los demás".

"Fundamentalmente esta muestra está dirigida a los jóvenes, más a los estudiantes, para que ellos puedan apreciar los innumerables inconvenientes de tipo conceptual y técnico que he tenido y sigo teniendo como los tienen todos ellos. Pero que también sientan que el buscar soluciones es un ejercicio apasionante que va templando el alma. Esta lucha permanente con materia y forma para expresar un contenido intangible, los dignifica ante el mundo y los proyecta como seres sensibles, en definitiva, ¿no es esto la felicidad?".

\section{NOTAS AL TRABAJO "MEDITACION DEL CHACO Y AMERICA EN LA OBRA DE UN PINTOR ARGENTINO".}

1.- Para la historia del emplazamiento, población, desarrollo histórico, económico, social y artistico de Resistencia, consultar: E. Bruniard - A. Bolsi, "El proceso histórico y los caracteres demográficos y socioeconómicos de la ciudad de Resistencia" en Folia Histórica del Nordeste, № 1, 1974, U.N.N.E.; Folia Histórica del Nordeste №3 de 1978 dedicada a los cien años de Resistencia,varios trabajos sobre la capital del Chaco: ferrocarriles, caminos de acceso, la vivienda en el período 1920-1947. En ambos números de la revista se menciona bibliografia específica y clásica sobre el tema. Tambien, Carlos López Piacentini, Historia de la provincia del Chaco, ed. Chimán, Buenos Aires, 1969-1970, tomos 1 y II. El desarrollo cultural de Resistencia en, G. Miranda - J. C. Vidarte, El rostro cambiante del Chaco, ed. Cultural Nordeste, Resistencia, 1973; G. Miranda, Los murales de Resistencia, ed. Cultural Nordeste, 1973; sobre Resistencia de 1920 y 1956-1958, referencias en mi art. "Dos monumentos fundacionales" en el libro Testimonios, U.N.N.E., Resistencia, 1983; E. Baliari, El Chaco y su cultura: esculturas l, ed. Inca, Bs. As., 1979, texto en castellano, inglés y portugués con ilustraciones de las esculturas emplazadas en las calles de Resistencia. 
2.- El Certamen Nacional de Escultura en Madera, desde su primera convocatoria en 1988, hasta el momento de la impresión de este número de Cuadernos de Literatura, ha ganado en espacio de convocatoria, en calidad de obras y autores y en organización. Actualmente la Fundación Urunday, nacida del impulso y trabajo del escultor Fabriciano Gómez y un grupo de artistas chaqueños, empeñosos y persistentes en las metas que se proponen, organiza este año 1994 el Segundo Concurso Trienal Internacional de Escultura en Madera. El ámbito de trabajo sigue siendo el mismo, la Plaza 25 de Mayo de Resistencia. El entusiasmo de los participantes y los interesados en verlos crear sus esculturas crece de año en año.

El Salón Nacional de Dibujo y Grabado, lamentablemente ya no se realiza. En cambio hay exitosas convocatorias a certámenes y jornadas a estudiantes de Bellas Artes para realizar grabados en madera en la misma plaza, con la orientación de grabadores conocidos en el medio, como Beatriz Moreiro.

El canto coral sigue siendo una actividad muy cultivada en Resistencia, cuya Asociación Coral Polífónica es dirigida por Pedro Múscar, talentoso discipulo de Yolanda Pereno de Elizondo.

3.- Este clima se logra por la labor de instituciones nacidas con fines desinteresadamente culturales y de hombre que trabajaron en forma continua por mejorar la fisonomía espiritual del Chaco. Instituciones como el Ateneo del Chaco, de recordada labor entre los años ' 30 y ' 40 , hasta los '60; el Fogón de los Arrieros, nacido en 1943 con los hermanos Aldo y Efraín Boglietti, quienes promueven la venida a Resistencia de importantes figuras del arte y la cultura del pais y del exterior; desde 1962 empiezan a poblar las calles de la ciudad con estatuas. A ello se suma desde 1958 la acción de la Facultad de Humanidades. La transformación del clima cultural se nota en estos diez últimos años.

\section{4.- Carlos López Piacentini, op. cit.}

5.- El Dr. Oberdan Caletti, Decano de la Facultad de Humanidades, crea por Res. Ne 68 de 1958 el Taller de Arte Regional, para desarrollar en los jóvenes del nordeste las inclinaciones artísticas que manifiestan. Carlos $\mathrm{H}$. Schenone fue su organizador y primer director hasta 1963, año de su muerte. Desde 1971 se denomina Taller de Artes Visuales.

6.- Hilda Torres Varela en el prólogo al libro El Chaco y su cultura, antes citado, proporciona una nutrida nómina de pintores y escultores famosos que permanecieron trabajando por largos o breves períodos en el Fogón de los Arrieros, desde 1944 a 1960. Esta mención da la medida del movimiento cultural de Resistencia y cómo sus habitantes pudieron conocer las obras, escuchar y tratar a sus autores, enriqueciéndose con esta cercania. Entre los años '60 y '70, mientras desarrollaba su labor el Instituto Di Tella en Buenos Aires, Resistencia no estuvo ajena a los movimientos artísticos de moda en la Capital Federal. 
7.- Jorge Taverna Irigoyen lo llama autodidacta en su art. del 9.9 .66 en el diario El Litoral de Santa Fe. César Magrini en 1973 elogia su "asombrosa madurez de oficio", logro de su disciplinado trabajo. En el reportaje del periodista Guillermo Sánchez de L.T.5 Radio Chaco en agosto de 1977, Rodolfo Schenone se define: "Yo esencialmente soy autodidacta, me he desarrollado así; estudio desde que tengo uso de razón, trato de aprender a través de todo lo que me llega y en todas las oportunidades que tengo de estudiar, lo hago".

8.- El artista tuvo siempre esta meta, aunque en sus comienzos el logro no se veía con la nitidez de estos últimos diez años. En 1968 decía: "Lo que puede definir mi obra es la temática: el habitante chaqueño con proyección universal, sus problemas sociales -no desde un punto de vista político- enfocados desde su resonancia humana. Sólo pretendo dejar un testimonio de lo que me rodea, nacido de una íntima fusión con la región, arraigado en mi desde mis primeros años. Quiero plasmar en mis obras no solamente problema y desventuras, sino también alegrías, el temple de esta gente que lucha para justificar la vida". (El Territorio, Resistencia, 24.11.68). En 1985 declara: "Mis sentimientos me inducen al esfuerzo por lograr símbolos de los misterios de mi tierra, en una búsqueda de lo absoluto y trascendente hacia una comunicación universal". (El Litoral, Santa Fe, 29.4.85).

9.- César Magrini en El Cronista Comercial, Buenos Aires, 10.5.73. Artículos de Jorge Taverna Irigoyen en El Litoral de Santa Fe el 25.8.65; el 9.9.66; 10.6.72; el 16.7.81 y su prólogo a mi libro Rodolfo Schenone: vida y arte, ed. Región, Resistencia, 1985. Vicente Caride en la presentación del Catálogo de la Exposición en la Galería Nice de Buenos Aires en junio de 1974. Ver más bibliografla sobre la obra de Rodolfo Schenone en mi libro arriba mencionado.

10.- Los premios obtenidos en 1972 fueron más numerosos que en otros años: Gran Premio de Honor en Pintura y Primer Premio en Escultura del V Salón del Nordeste, Resistencia. El Sindicato de Prensa del Chaco le otorga la "Galera de Honor" como valor más destacado en Pintura en 1972. En el VII Salón del Litoral de la Provincia de Entre Ríos obtiene el Premio "Ministerio de Bienestar Social". Es designado el Valor más representativo del Chaco en la Bienal de Valores Plásticos del Interior organizado por la Subsecretaría de Cultura de la Nación. Obtiene el Primer Premio en el Salón de Artistas Visuales del Interior organizado por la Municipalidad de Buenos Aires.

Nota: el texto básico de este trabajo fue leido en el Congreso Internacional "V siglos de Hispanidad" organizado por los Institutos Argentinos de Cultura Hispánica y realizado en la ciudad de Córdoba, Argentina, del 24 al 27 de mayo de 1990. La autora ha revisado y actualizado el mismo, especialmente para los CUADERNOS DE LITERATURA № 6, del instituto de Letras de la U.N.N.E., en diciembre de 1992. 



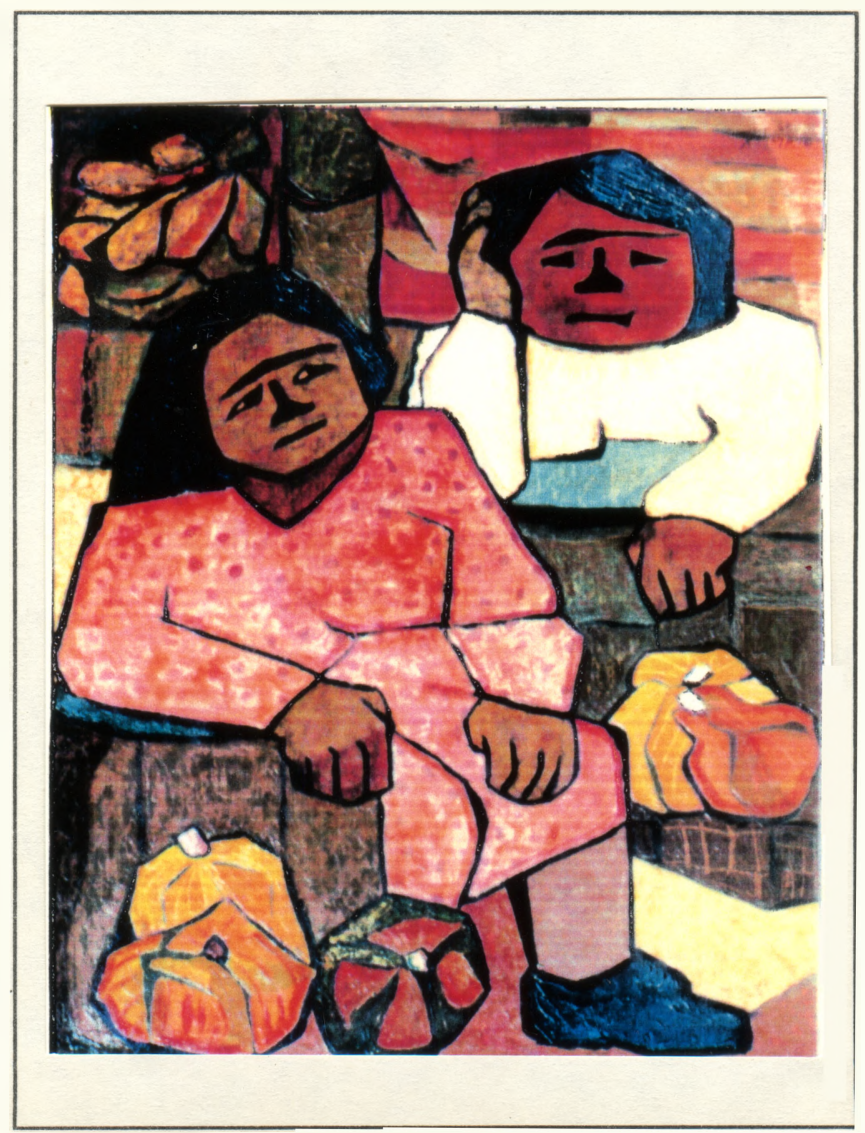

Rodolfo Schenone

Muchachas en la féria. Óleo 1968. 


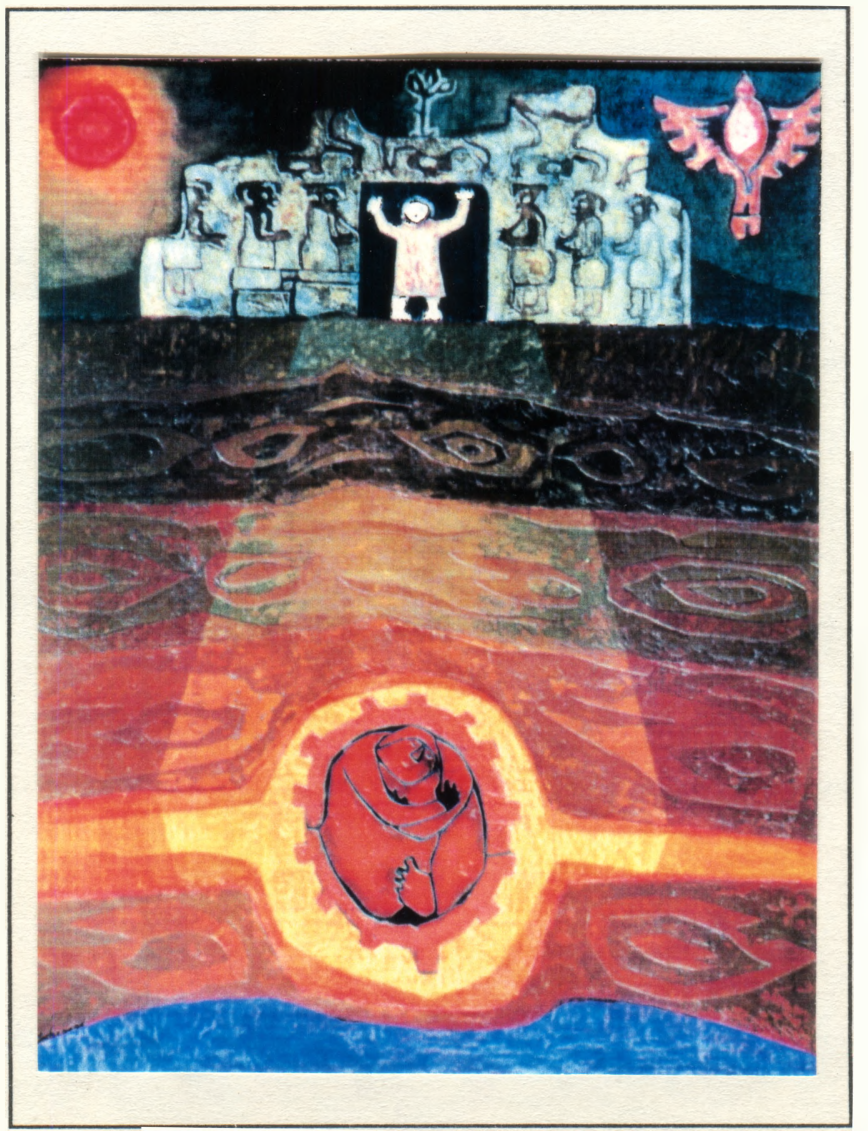

Rodolfo Schenone .

Génesis de la Tierra. Óleo 1972. 


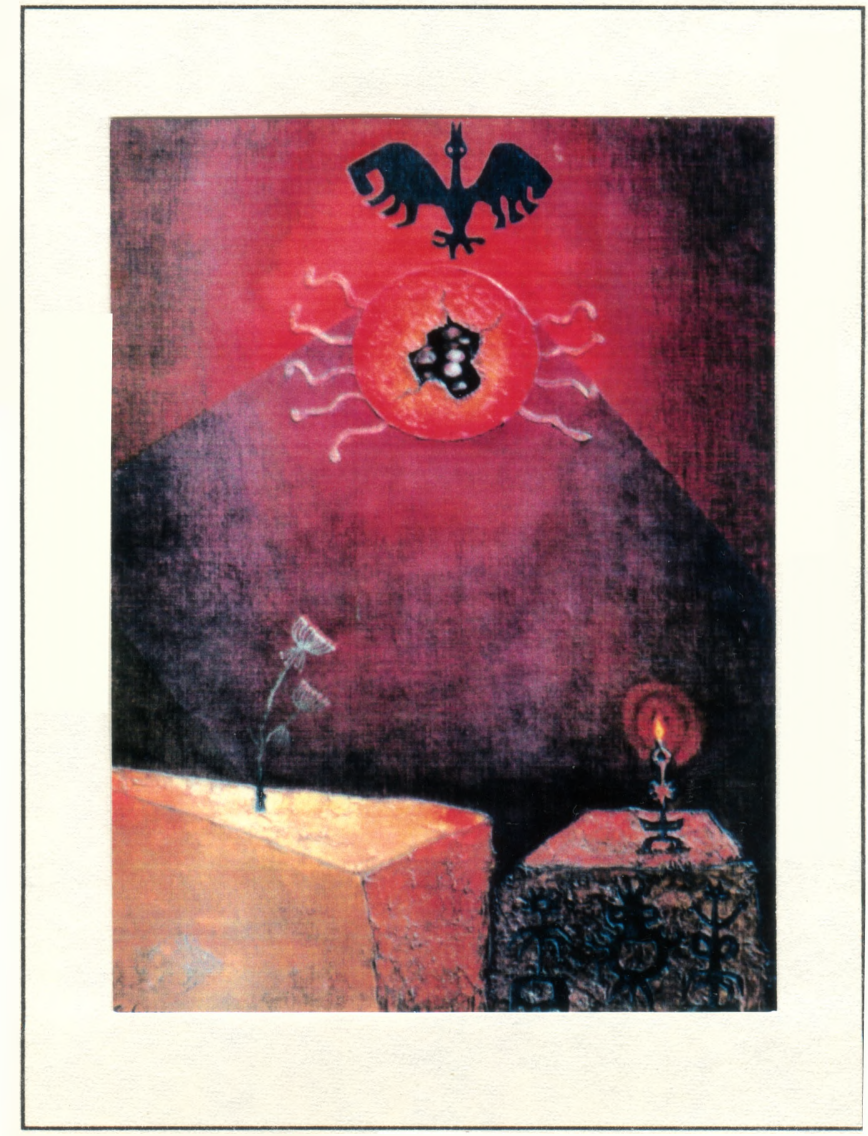

Rodolfo Schenone

Padre Sol. Oleo 1976 


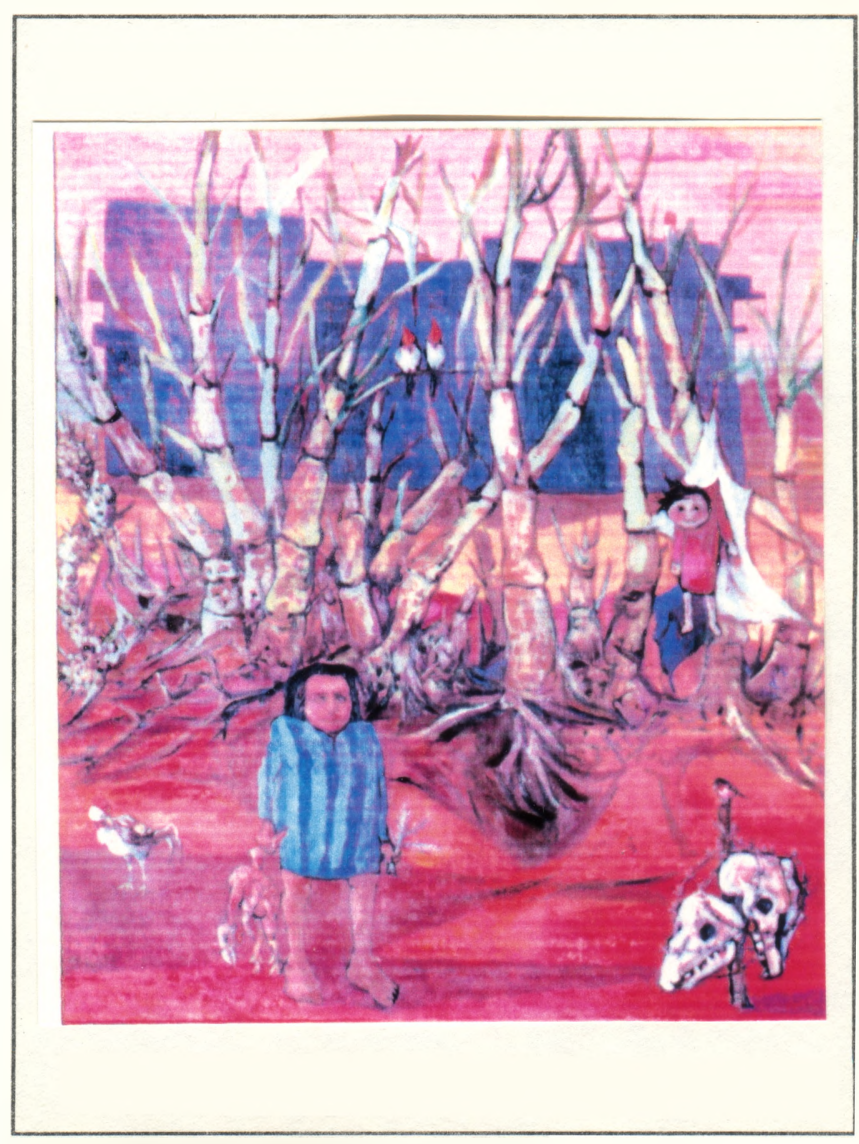

Rodolfo Schenone

Cansancio del Alma. Óleo 1992. 